Article

\title{
A Probabilistic Classification Procedure Based on Response Time Analysis Towards a Quick Pre-Diagnosis of Student's Attention Deficit
}

\author{
M. Hernaiz-Guijarro ${ }^{1}$, J. C. Castro-Palacio ${ }^{2, *}$, E. Navarro-Pardo ${ }^{3}{ }^{\complement}$, J. M. Isidro ${ }^{1}(\mathbb{D}$ and \\ P. Fernández-de-Córdoba ${ }^{1}$ (D) \\ 1 Instituto Universitario de Matemática Pura y Aplicada, Grupo de Modelización Interdisciplinar, InterTech, \\ Universitat Politècnica de València, E-46022 Valencia, Spain; moihergu@doctor.upv.es (M.H.-G.); \\ joissan@mat.upv.es (J.M.I.); pfernandez@mat.upv.es (P.F.-d.-C.) \\ 2 Institute of Nuclear Fusion, ETSII, Universidad Politécnica de Madrid, c/José Gutiérrez Abascal, 2, \\ 28006 Madrid, Spain \\ 3 Departamento de Psicología Evolutiva y de la Educación, Grupo de Modelización Interdisciplinar, InterTech, \\ Universitat de València, E-46010 Valencia, Spain; esperanza.navarro@uv.es \\ * Correspondence: juancarlos.castro@upm.es or juanccastro2007@yahoo.com
}

Received: 24 April 2019; Accepted: 22 May 2019; Published: 24 May 2019

\begin{abstract}
A classification methodology based on an experimental study is proposed towards a fast pre-diagnosis of attention deficit. Our sample consisted of school-aged children between 8 and 12 years from Valencia, Spain. The study was based on the response time (RT) to visual stimuli in computerized tasks. The process of answering consecutive questions usually follows an ex-Gaussian distribution of the RTs. Specifically, we seek to propose a simple automatic classification scheme of children based on the most recent evidence of the relationship between RTs and ADHD. Specifically, the prevalence percentage and reported evidence for RTs in relation to ADHD or to attention deficit symptoms were taken as reference in our study. We explain step by step how to go from the computer-based experiments and through the data analysis. Our desired aim is to provide a methodology to determine quickly those children who behave differently from the mean child in terms of response times and thus are potential candidates to be diagnosed for ADHD or any another cognitive disorder related to attention deficit. This is highly desirable as there is an urgent need for objective instruments to diagnose attention deficit symptomatology. Most of the methodologies available nowadays lead to an overdiagnosis of ADHD and are not based on direct measurement but on interviews of people related to the child such as parents or teachers. Although the ultimate diagnosis must be made by a psychologist, the selection provided by a methodology like ours could allow them to focus on assessing a smaller number of candidates which would help save time and other resources.
\end{abstract}

Keywords: attention deficit hyperactivity disorder (ADHD); reaction time; ex-Gaussian analysis

\section{Introduction}

Among cognitive disorders, attention deficit hyperactivity disorder (ADHD) common in children and can be present until an adult age in about $30-50 \%$ of cases [1,2]. It usually comes with problems paying attention, hyperactivity and impulsive behavior [3]. There are other elements associated with ADHD such as behavior problems, low academic performance, rejection, non-compliance with others, with others, and lack of social skills [4,5]. These educational and psychosocial consequences that come with ADHD and have long-term impact can be alleviated with early assessment and treatment [6]. An estimate of the world prevalence percentage of ADHD is 5-7\% in school-aged children (American Psychiatric Association, 2013). 
The process of diagnosing ADHD is somewhat long and tedious compared to the diagnosis of other mental disorders [7]. According to the American Academy of Child and Adolescent Psychiatry (AACAP), the assessment of ADHD should include collecting information from the parents, school, interviews with the child, and gathering information about the overall functioning of the child, including the child's medical, social, and family histories [8]. Given the fact that performing a good diagnosis of ADHD may be a difficult and long task to do, it is desirable to count on a methodology capable of determining quickly those children more likely to be diagnosed with ADHD. Based on this first screening, clinicians can make a more definite diagnosis. A methodology with these features may contribute enormously to saving resources and serve as a guide to psychologists.

Previous work [9] has reported that children suffering from ADHD can be impulsive and respond faster than other children. On the other hand, their performance is very slow in cognitive tasks. Their mean response times are higher independently from the specific ability being tested [10-12]. Overall, children with ADHD show both very fast and very slow responses and thus present a high intra-individual variability (IIV) [13].

Response time distribution are positively skewed [14] and thus are not properly described by standard central tendency estimators, for instance, the mean and standard deviation $[15,16]$. In this respect, the ex-Gaussian function has been proven to optimally fit the probability distribution curves of the RT $[17,18]$. This function results from a convolution of a Gaussian and an exponential function [19] from where, there interpretable parameters result: $\mu, \sigma$, and $\tau[15,20]$. Parameters $\mu$ and $\sigma$ come from the Gaussian function and $\tau$ from the exponentially distributed component, which relates to the positive skew of the RT distribution. Where the data are represented by ex-Gaussian function, trimming of the data is not necessary which may lead to a subjective variation of the sample by removing extremely high RT values treated as outliers.

There are a number of works in the literature where the ex-Gaussian function is used to represent the RT data and interpret its parameters $\mu, \sigma$, and $\tau$ in relation to cognitive disorders. For instance, parameters $\sigma$ and $\tau$, along with the standard deviation of the ex-Gaussian function have been found to be related to ADHD in adults. Similarly, correlation was found between $\tau$ and the rate of omission errors [17]. In the case of youth with ADHD, the ex-Gaussian analysis revealed larger standard deviation and parameter $\tau$ (of the exponential component) [21]. In Reference [22], the authors, studied ADHD and autism spectrum disorder (ASD) in children aged 7-10 years to gain insights into the attentional fluctuations, related to increased response time variability. The ex-Gaussian parameters are claimed to be clearly correlated with cognitive processes such as attention. The exponential component $\tau$ seems to be diagnostic of ADHD particularly in boys [23]. However, the authors in Reference [18] determined that this is not absolutely true, as the ex-Gaussian parameters may not correspond uniquely to specific cognitive processes. In this respect, they point out that researchers should be more careful when examining the changes in the ex-Gaussian parameters.

In summary, when it comes to interpreting the ex-Gaussian parameters, children showing a combination of higher $\mu$ values and low $\tau$ values are more likely to have slower response times. On the other hand, children showing lower values of the parameter $\mu$ and higher values of $\tau$ correlate with much faster or much lower responses. The representation of the data in terms of an ex-Gaussian distribution has been a common procedure whose benefits have been widely discussed in the literature [24-27].

The main advantage of the ex-Gaussian analysis consists of its three parameters may be correlated with cognitive processes [26], although there is a large debate about the functional interpretation of these parameters [21]. In this respect, $\tau$ seems to be the parameter attracting the most attention and has been described as a perceptual aspect of RT [28], related to decision [14] and in more recent works, as a defective effort control mechanism or attentional component [23]. In addition, there are plenty of works in the literature supporting the idea of interpreting the response time in computerized tasks in terms of ex-Gaussian parameters as a useful approach to gain access to a more sensitive and specific measure of variability in patients with ADHD [29]. 
In this work, a response time classification methodology based on an experimental study is proposed towards a quick pre-diagnosis of attention deficit or any another cognitive disorder related with it. Our sample consisted of school-aged children between 8 and 12 years from Valencia, Spain. Response times (RTs) were collected from computerized tasks based on visual stimuli.

First, we aimed to find the empirical probability distribution for the response time which can be considered the normative behavior of a child in the population that was explored. Subsequently, we proposed a classification methodology that identified those children lying furthest from the normative behavior of a child. The RT data were represented in terms of the ex-Gaussian function and its three parameters. Subsequently, the probability distributions of these parameters and of the mode were used to establish a classification methodology. The ex-Gaussian parameters were also considered in a more global approach as components of a vector, which is associated to each child through its norm definitions.

Our main hypothesis is that, taking into account the prevalence percentage of ADHD in general, childhood population, and the most recent evidence of the relationship between RTs and attention deficit in the literature, we should be able to establish a simple automated classification scheme of children with attention deficit based on their statistical RT distribution to visual stimuli.

We explain in detail all stages followed in the data analysis. Our ultimate aim was to provide a classification methodology to determine, without going through the entire diagnosis process, those children who may be behaving differently from the mean child regarding attention deficit and thus are potential candidates to be diagnosed with ADHD or any another cognitive disorders. This is the first part of a series of works on classification methodologies based on different representations of the RT data and their relationship with cognitive disorders.

\section{Materials and Methods}

\subsection{Participants}

A sample of 190 children (95 males and 95 females) with ages between 8 and 12 years. The age distribution of the sample is shown in panel a) of Figure 1. The overall mean age was 9.5 years, with a standard deviation (SD) of 1.3 years. The mean ages and standard deviations of females and males were $9.4(\mathrm{SD}=1.3)$ and $9.7(\mathrm{SD}=1.2)$ years, respectively. The differences were not statistically significant. The children who participated in the experiments attended a primary school in Valencia (Spain). This public school is located in the La Patacona District of Alboraia municipality. We obtained all necessary consents and authorizations at all necessary levels, namely, the children's parents, the Direction of the School, and the City Council. This study was carried out in accordance with the recommendations of the Secretariat of Education of the Valencian Community. The protocol was approved by the Government of Valencia (Generalitat Valenciana). The due written consent of the children's parents or legal guardians was obtained in accordance with the Declaration of Helsinki [30]. The children forming our sample were not previously diagnosed with ADHD. The children participating in the computerized experiments had never had any health issue, such as any seizures, brain injury or any other neurological damage, which could bias the results by mimicking ADHD. This information was obtained from parents and from school psychologists, who assessed all the children at the start of primary school and continued to assess them biannually. 
a)

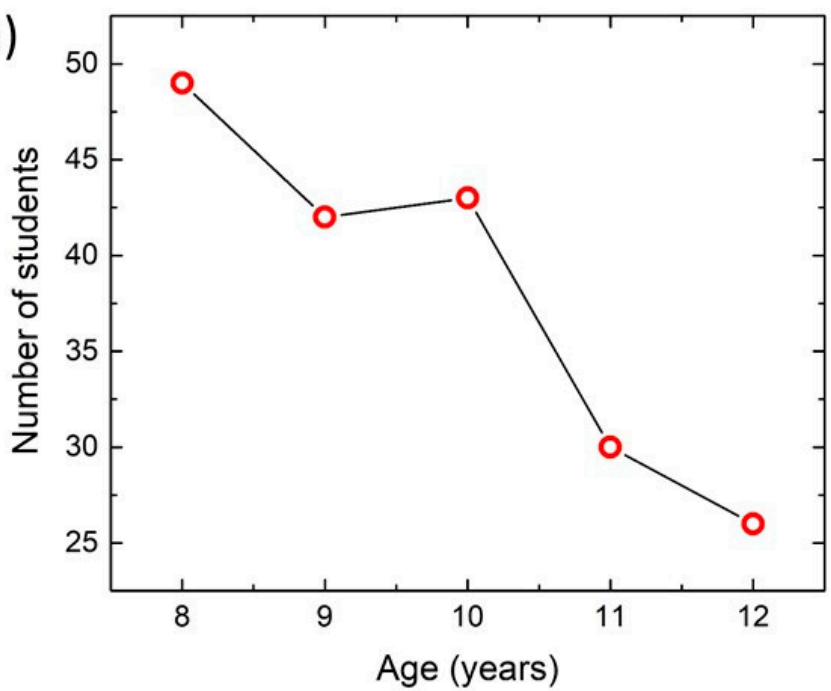

b)

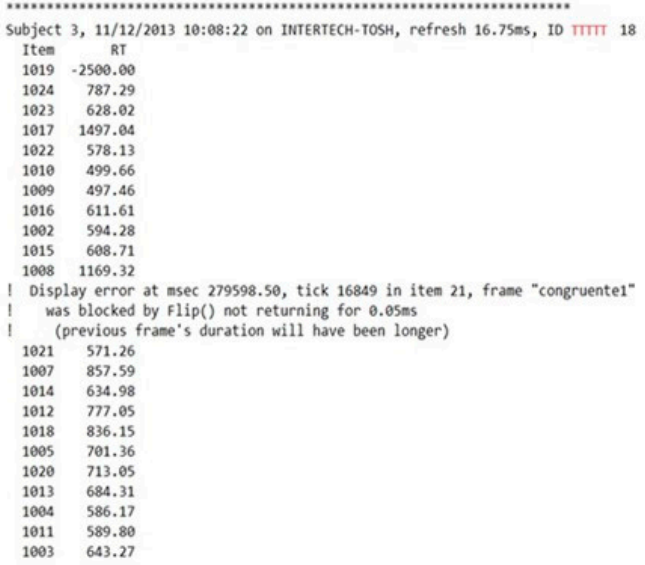

Figure 1. The age distribution of the sample is shown in panel (a) and a fragment of a *azk output file in panel (b). In order to protect the privacy of the child who performed the experiment, the characters "TTTTT" have been used as a pseudonym for the actual name.

\subsection{Experiments with $D M D X$}

Computer-based experiments were carried out through the Windows program DMDX [31] widely used in the community of experimental and cognitive psychologists [26,32]. By means of this program, stimuli were presented to the participants and RTs recorded. The tasks applied in this work were designed by psychologists of the Interdisciplinary Modeling Group InterTech (www.intertech.upv.es), a team from both the Polytechnic University of Valencia and the University of Valencia, Spain. Experiments were carried out in a quiet classroom and using laptop computers bearing DMDX software. Each experiment lasted for 6-7 min and stimuli were presented randomly to avoid order presentation effects.

The experiments included an attention network task (ANT) [32] which seeks testing three attentional networks: alerting, orienting, and executive control. Alerting network is assessed by changes in reaction time as a result of a warning signal. Orienting is related with changes in the RT indicating where the target will take place. Finally, the efficiency of the executive control is carried out by asking the children to answer by pressing the keys in indicating left or right direction of an image placed at the center in between neutral, congruent or incongruent flankers. These three networks are very related among them $[33,34]$. Each stimulus consisted of 5 fish aligned horizontally looking at the right or the left (Figure 2a). The color is black and the background is white. The objective of the task was to identify, in each trial, the direction of the central fish. There were three cases depending on the 
orientation of the fish around the central one. The neutral case was when there was only the central fish. The congruent case was where the surrounding fish were placed in the same direction as the central fish. The third case was where the surrounding fish were placed in the opposite direction in respect to the central one. If the central fish was facing right, the key labeled " $\mathrm{M}$ " should be pressed, if not, the key labeled " $Z$ " should be pressed (Figure 2a). Four cue conditions anticipated the appearance of the target, namely, "no cue", "central cue", "spatial cue", and "double cue" which vary depending on the stimulus (Figure 2b). A total of 144 stimuli were presented in a random way and for a maximum of $2500 \mathrm{~ms}$ or until the child pressed a key.

a)

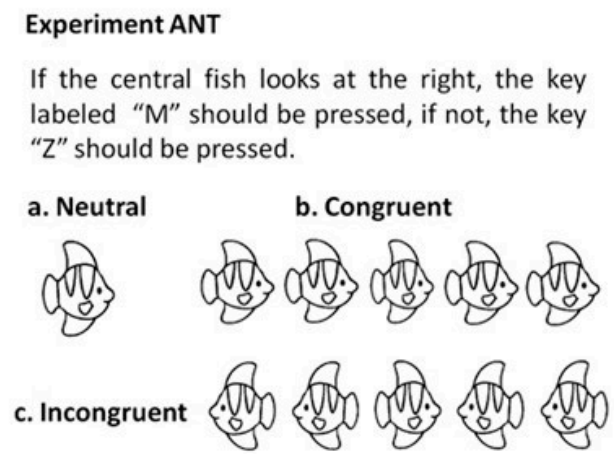

b)

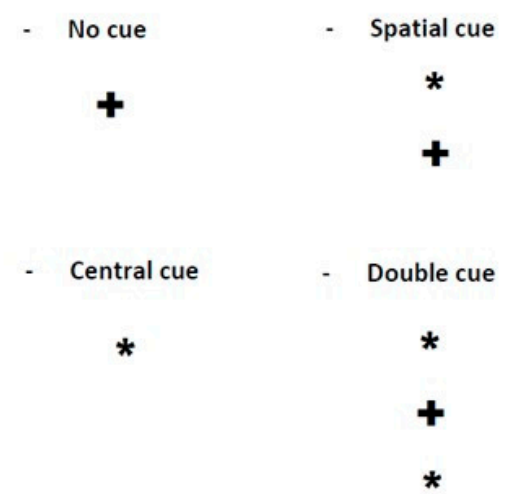

Figure 2. In panel (a), a visual example of the attention network task (ANT) carried out in this work is shown whereas in panel (b), the four cue conditions are included.

\subsection{Procedure for the Data Analysis}

The results of the experiments performed on DMDX software were saved out to a file with the extension *.azk. Figure $1 \mathrm{~b}$ shows a fragment of this file. First, a heading with the computer and student data can be found. Just after, two columns are shown. The first named "ITEM" contains a number assigned to each item in the design of the experiments. The second column indicates the response time in milliseconds.

Two types of errors can be found in the output data. The first happens when the child does not react after the exposure time of the image $(2500 \mathrm{~ms})$ has passed. The second error takes place when the child does not respond correctly and presses the wrong key. Errors have not been analyzed in the present study, although they can correlate with attention deficit. This important aspect will be considered in full in a further article which is currently under way.

By using a home-made code written in FORTRAN, the output files (* ${ }^{*}$ azk) were filtered such that records with errors were not included. The data were organized in the new file with three columns. The first column was a number identifying each trial (child), the second was the item number in the experiment, and the third was the response time.

Once the output files were cleaned by removing the undesired records, histograms of the response times were constructed for each trial. Different bin widths were tried out. The optimal bin size used to construct the histograms was $50 \mathrm{~ms}$. Subsequently, probability distribution functions were calculated by means of dividing the counts per bin by the total number of counts. The probability distribution functions were the starting point for the statistical analysis carried out in this work. In a first part, descriptive statistics were used and in the second an ex-Gaussian analysis with the corresponding interpretation of the three parameters of this function.

\section{Results and Discussions}

Figure 3 summarizes the results from filtering the output data (.azk files) obtained with DMDX program for the tasks considered in this work. Specifically, it shows the averages over the probability density curves corresponding to the data obtained with each laptop computer used to carry out the 
experiments. It can be seen that the DMDX program corrects properly the timing differences among the microprocessors. The number of response times included in each average is indicated between parentheses. It can be also noticed that all curves almost overlap and peak around $575 \mathrm{~ms}$ approximately.

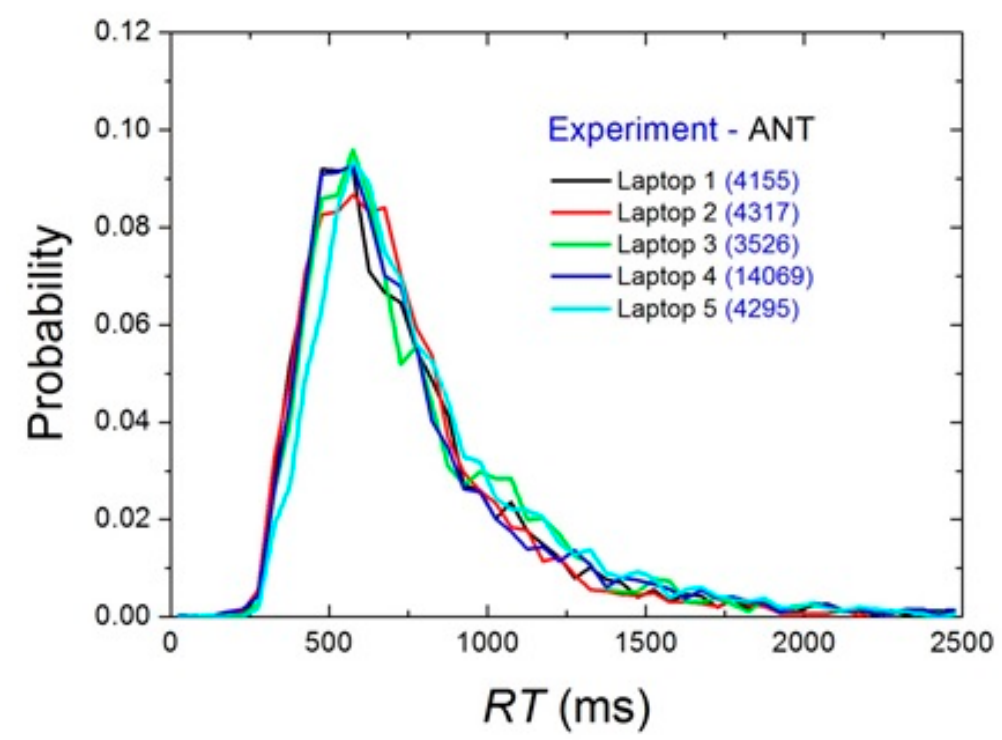

Figure 3. Comparison of the outputs from the different laptop computers used in the experiments.

The probability distributions of the RTs are shown in Figure 4. These curves where obtained from the histograms by dividing the number of counts corresponding to each bin over the total number of counts. The bin-by-bin average curve is represented along with the single curves. We worked with a sample of children who had not been diagnosed with ADHD before; however, there may occur a 7\% prevalence rate within the sample. In any case, we assumed that this $7 \%$ would not significantly vary the mean curve shown in Figure 4, which represents the average child.

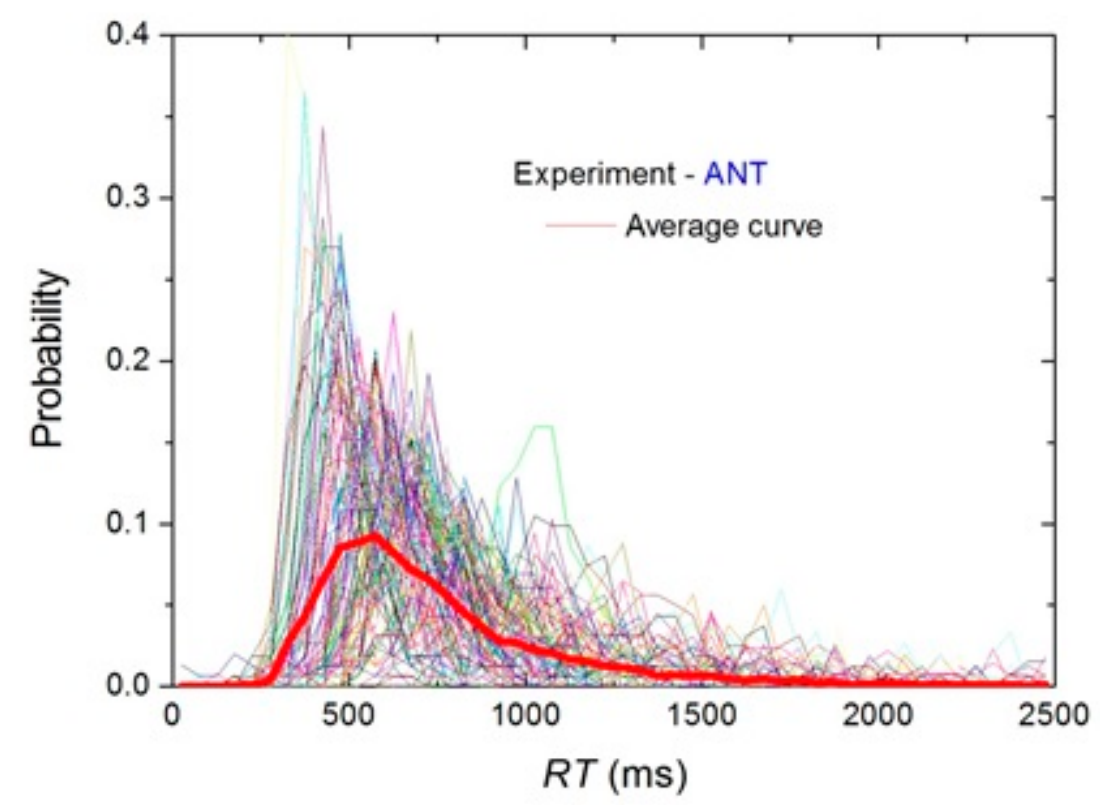

Figure 4. Probability distributions and average curve. 


\subsection{Ex-Gaussian Analysis}

In order to represent the RT data, we have chosen the ex-Gaussian distribution which has proven to be a good fit in previous works [35,36]. Our sample size is in line with Ratcliff et al. [37], who have suggested that samples with at least 100 data points are considered reliable as for parameter estimates. As commented in the Introduction section, the ex-Gaussian distribution relates three parameters: $\mu$ (the mean of the Gaussian component), $\sigma$ (the standard deviation of the Gaussian component), and $\tau$, which is the decay constant of the exponential component. These parameters are claimed in multiple works to describe cognitive processes such as attention or effort control mechanism, although there is a big debate in the literature about their interpretation [21].

Among the different forms of the ex-Gaussian distribution we have chosen the following as this is the one incorporated in the professional software for data analysis, ORIGIN version 6.1 [https://www.originlab.com/], used here as a reference to test our FORTRAN code,

$$
f(x)=y_{0}+\frac{A}{t_{0}} e^{\frac{1}{2}\left(\frac{\omega}{t_{0}}\right)^{2}-\frac{x-x_{c}}{t_{0}}} \int_{-\infty}^{z} \frac{1}{\sqrt{2 \pi}} e^{\frac{y^{2}}{2}} d y,
$$

where $\mathrm{z}=\frac{\mathrm{x}-\mathrm{x}_{\mathrm{c}}}{\omega}-\frac{\omega}{\mathrm{t}_{0}}$.

In Equation (1), the parameters can be identified as $\mu=x_{C}, \sigma=\omega y \tau=t_{0}$, that is, in terms of the Gaussian and exponential functions parameters,

$$
\begin{gathered}
\mathrm{f}_{1}(\mathrm{x})=\frac{\mathrm{A}}{\mathrm{t}_{0}} \mathrm{e}^{-\frac{\mathrm{x}}{\mathrm{t}_{0}}}, \\
\mathrm{f}_{2}(\mathrm{x})=\frac{1}{\sqrt{2 \pi} \omega} \mathrm{e}^{-\frac{\left(\mathrm{x}-\mathrm{x}_{\mathrm{c}}\right)^{2}}{2 \omega^{2}}} .
\end{gathered}
$$

It should be pointed out that $\mu$ and $\sigma$ do not represent the mean and the standard deviation of the ex-Gaussian distribution. Instead, the true mean of the distribution is $M=\mu+\tau$, the variance $S^{2}=\sigma^{2}+\tau^{2}$, and the skewness $2 \tau^{3} / S^{3}$ [38]. In fact, one can characterize this distribution $f(x)$ through its moments. One can consider moments of this distribution centered either at the origin (raw moments), or centered at the corresponding average (central moments). Thus,

$$
M \equiv \int_{-\infty}^{\infty} x f(x) d x
$$

is the raw moment of order one, whereas,

$$
S^{2} \equiv \int_{-\infty}^{\infty}(x-M)^{2} f(x) d x,
$$

is the variance, or second central moment, of the random variable $\mathrm{x}$ with probability distribution $\mathrm{f}(\mathrm{x})$ and centered at $\mathrm{M}$. The positive squared root of the above, $\mathrm{S}$, is the standard derivation. On the other hand, the skewness $t$ of the distribution is defined as

$$
\mathrm{t} \equiv 1 / \mathrm{S}^{3} \int_{-\infty}^{\infty}(\mathrm{x}-\mathrm{M})^{3} \mathrm{f}(\mathrm{x}) \mathrm{dx}
$$

That is, the centered moment of order three, divided by the standard deviation cubed. Altogether, an ex-Gaussian distribution can be characterized through its three moments,

$$
\mathrm{a} \equiv\left(\mathrm{M}, \mathrm{S}^{2}, \mathrm{t}\right)
$$


The fitting parameters and their uncertainties were obtained by the non-linear fitting algorithm of Levenberg-Marquardt [39,40], implemented in the ORIGIN version 6.1 data analysis software.

\subsection{Classification Methodology}

As stated above, the main objective of this work was to provide a methodology for a fast determination of the children whose time reaction differs from the mean and thus are potential candidates to be diagnosed with ADHD. To do so, evidence from the literature was used as criteria in our automatic methodology. The main criterion came from the world prevalence percentage, $7 \%$ for school-aged children according to the American Psychiatric Association (American Psychiatric Association, 2013). We would like to point out that any more specific prevalence percentages can be used if available. Then, the prevalence percentage was split between slow and fast response time regions in the probability distributions. Previous work indicates that children with ADHD are likely to manifest rather low and fast responses in the RT distributions [41].

There is another criterion which has not been considered here but could be also included along with the previous ones. ADHD occurs about three times more often in boys than in girls, although some authors claim that the disorder is often overlooked in girls due to their symptoms differing from those of boys [42].

For our analysis we have considered four parameters. The mode, which is the value that appears most often in a dataset which is derived from descriptive statistics. This is a better descriptor than the mean value as the ex-Gaussian is a skewed distribution where the mean would not have a useful interpretation. The other three parameters come from the ex-Gaussian representation of the data, $\mu$, $\sigma$ and $\tau$, which have been widely related with ADHD in the literature [26,38].

To combine both criteria stated above in one, probability distributions have been built for each of the four parameters aforementioned, namely, for the mode and for ex-Gaussian distribution parameters. In order to account for the skewness of the probability distributions of each of the four parameters, the percentages of counts at both sides (left and right hand sides) of the mode, namely x_ "left" and $\mathrm{x}_{-}$"right", are determined from the corresponding number of counts, $\mathrm{N}_{-}$"left" and N_"right". Then, the prevalence percentage $(\mathrm{P})$ can be expressed as,

$$
\mathrm{P}=\mathrm{x}_{\mathrm{L}}+\mathrm{x}_{\mathrm{R}}=\left(\mathrm{N}_{\text {left }} / \mathrm{N}\right) 100+\left(\mathrm{N}_{\text {right }} / \mathrm{N}\right) 100 .
$$

We took the world prevalence percentage, $\mathrm{P}=7 \%$ [3] which is inclusive of both genders. We are aware that ADHD is more prevalent in males than females (4:1 ratio), and that this ratio tends to become 1:1 by the adult age [43]. This methodology as applied to our data, was reflected in Figures 5 and 6, where the probability distributions of the four parameters are shown along with the resulting splitting of the prevalence percentage for each case. The resulting candidates according to the split percentages were included in Table 1, and in Figures 7 and 8. It should be considered that those candidates with a very fast response time may also include skilled children who are able to answer the experiment's queries both correctly and quickly. If the fast-responding children make a considerable number of mistakes, that could be used as a complementary criterion for the selection of ADHD candidates. 

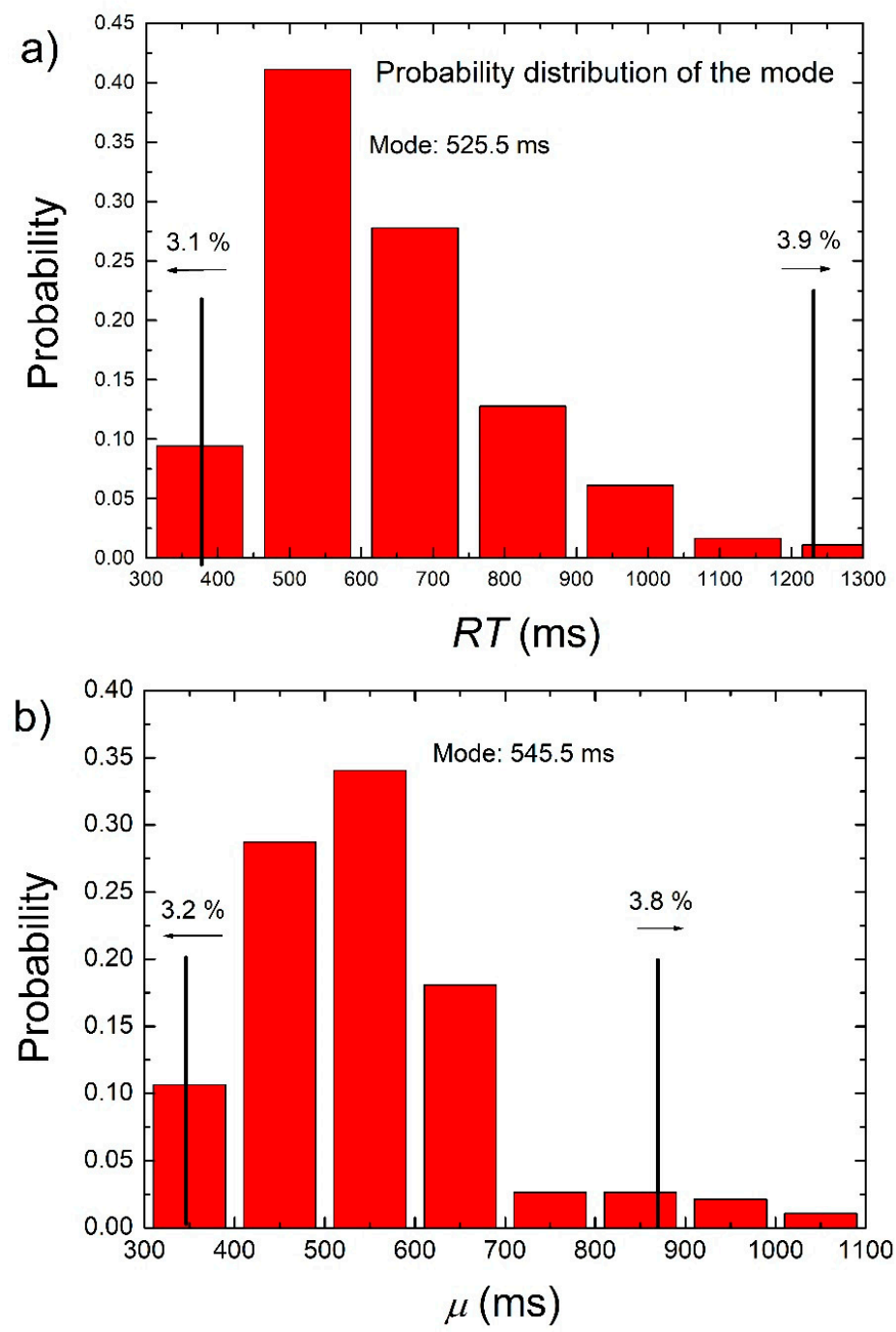

Figure 5. Probability distributions of the mode (a) and of $\mu$ parameter in an ex-Gaussian representation of the data $(\mathbf{b})$.

Table 1. Results of the classification for the distribution of the mode, $\mu, \sigma$ and $\tau$ (columns from second to fifth) taking into account a $\%$ of world prevalence of ADHD in school-aged children. The rows show the mode, the probability percentages at both sides of the mode (\%-PD), the splitting of the prevalence percentage (\%-Prev.), corresponding number of children (No. Ch.), and the selected children in terms of labels.

\begin{tabular}{|c|c|c|c|c|c|c|c|c|}
\hline \multirow{3}{*}{ Mode (ms) } & \multicolumn{2}{|c|}{ Mode } & \multicolumn{2}{|c|}{$\mu$} & \multicolumn{2}{|c|}{$\sigma$} & \multicolumn{2}{|c|}{$\tau$} \\
\hline & \multicolumn{2}{|c|}{525.5} & \multicolumn{2}{|c|}{545.5} & \multicolumn{2}{|c|}{87.5} & \multicolumn{2}{|c|}{112.5} \\
\hline & L & $\mathbf{R}$ & $\mathbf{L}$ & $\mathbf{R}$ & L & $\mathbf{R}$ & L & $\mathbf{R}$ \\
\hline$\%-P D$ & 44.4 & 55.6 & 45.0 & 55.0 & 16.5 & 83.5 & 14.9 & 85.1 \\
\hline \%-Prev. & 3.1 & 3.9 & 3.2 & 3.8 & 1.2 & 5.8 & 2.0 & 5.0 \\
\hline No. Ch. & 6 & 7 & 6 & 7 & 2 & 11 & 2 & 11 \\
\hline $\begin{array}{l}\text { Selected } \\
\text { children } \\
\text { (labels) }\end{array}$ & \multicolumn{2}{|c|}{$\begin{array}{c}2,28,34,55,77,75 \\
130,85,102,107 \\
134,142,159\end{array}$} & \multicolumn{2}{|c|}{$\begin{array}{c}28,34,55,58,75,77 \\
80,102,106,130 \\
163,167,184\end{array}$} & \multicolumn{2}{|c|}{$\begin{array}{c}5,39,41,58,71,80,85 \\
109,130,136,141,183,184\end{array}$} & \multicolumn{2}{|c|}{$\begin{array}{c}5,28,34,55,58,80,109 \\
113,133,136,163,183,187\end{array}$} \\
\hline
\end{tabular}



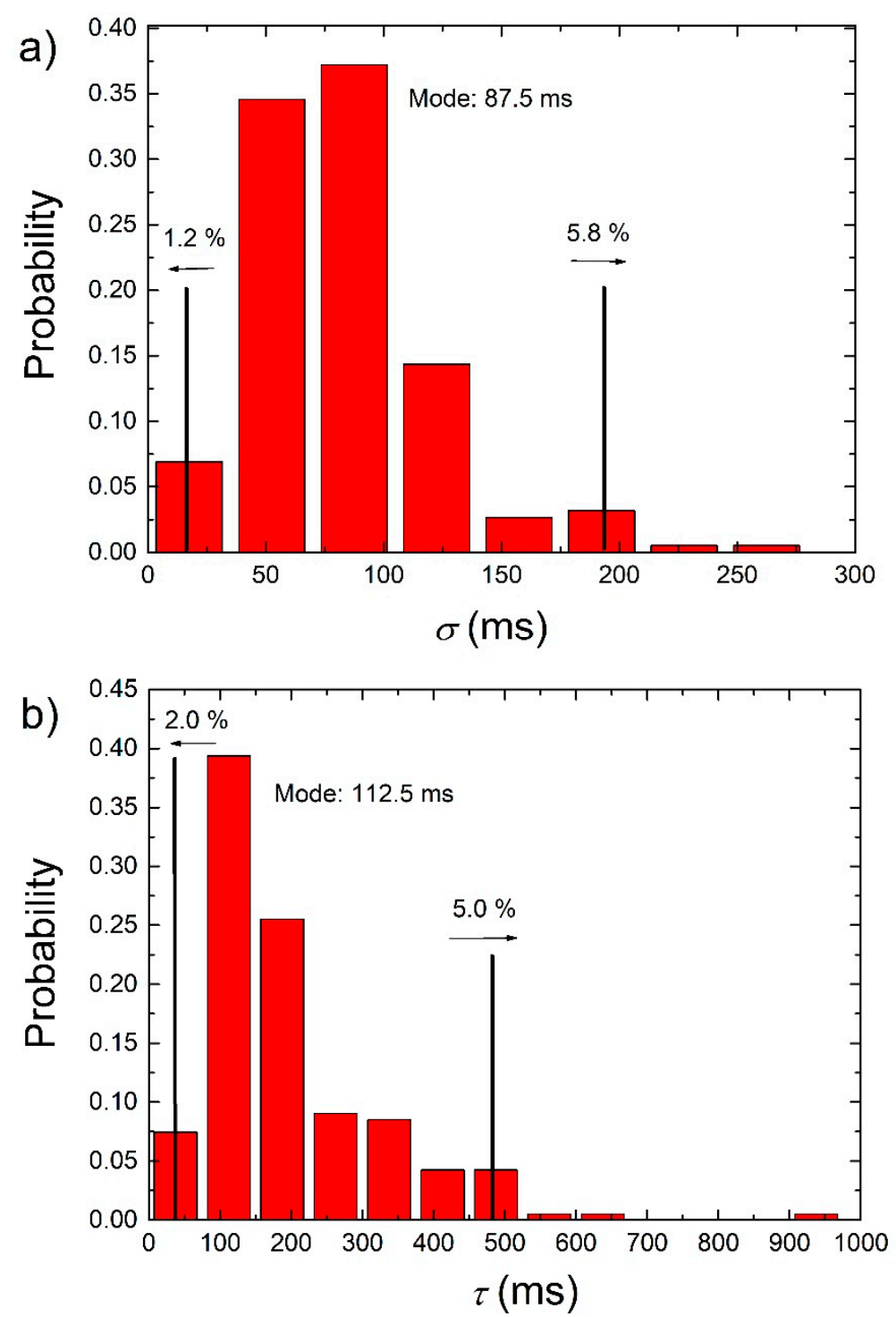

Figure 6. Probability distributions of $\sigma(\mathbf{a})$ and $\tau(\mathbf{b})$ parameters in an ex-Gaussian representation of the data.

Previous work, where the ex-Gaussian function was used to represent the RT data in children with ADHD, seem to indicate that ADHD correlates with slow response times and high RT variability, namely, large values for $\boldsymbol{\sigma}$ and $\boldsymbol{\tau}$ parameters $[22,44]$. This is one of the reasons why we are including here the probability distribution of the ex-Gaussian function parameters as well. 

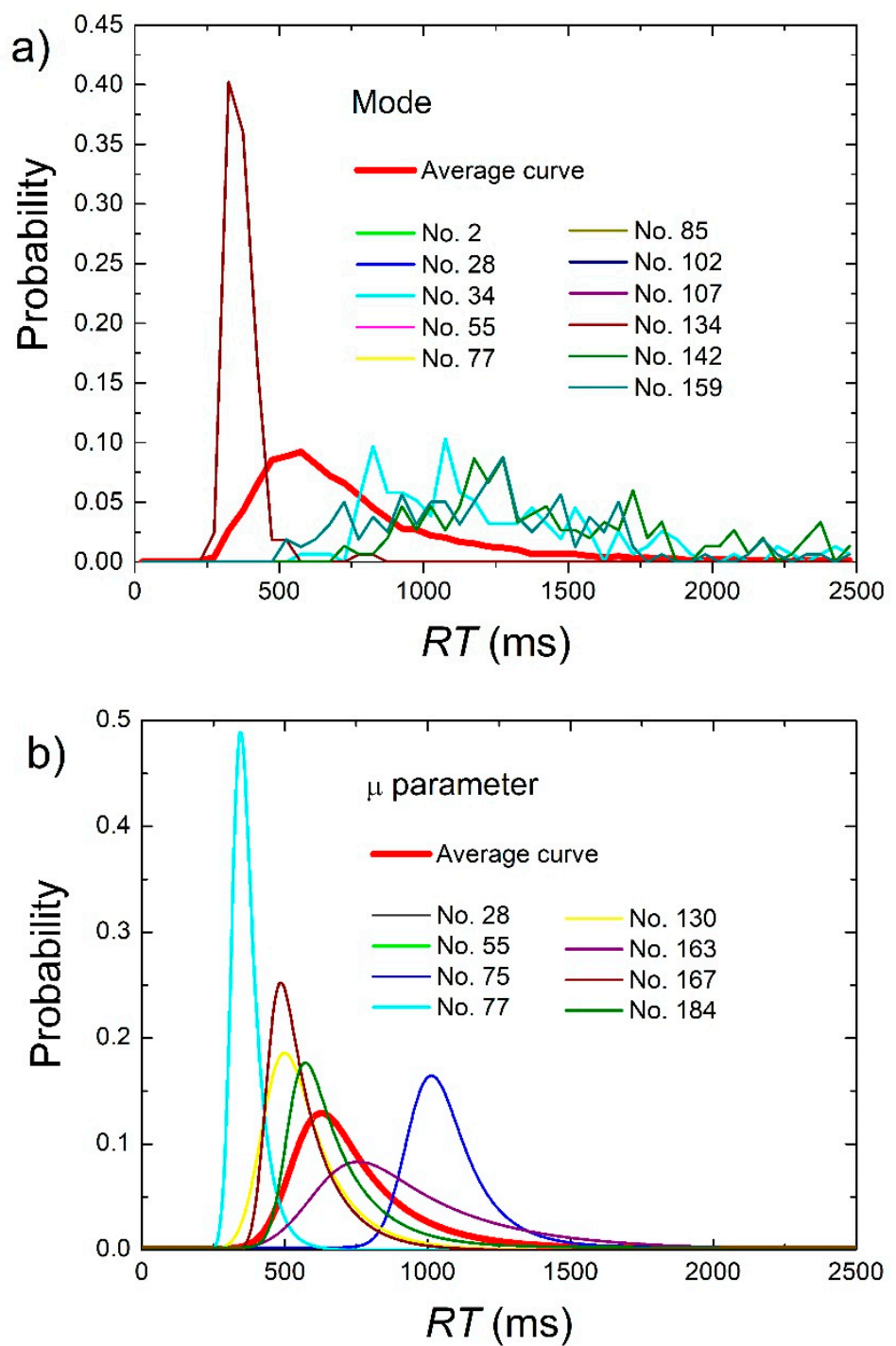

Figure 7. Probability distributions of the candidates resulting from the probability distribution of the mode in panel (a) and of the candidates resulting from the probability distribution of the parameter $\mu$ in panel (b). The average curve has also been included.

\subsection{Vector Criterion Based on the Ex-Gaussian Parameters}

A number of $\mathrm{N}=190$ vectors, of three components each, was defined over the parameters of the ex-Gaussian distribution for each student. The components of each vector were calculated as the difference of each student's parameter $\left(\mu_{i}, \sigma_{i}\right.$, and $\left.\tau_{i}\right)$ with respect to the mode of the corresponding parameter's probability distribution $\left(\mathrm{M}^{\mu}, \mathrm{M}^{\sigma}\right.$, and $\left.\mathrm{M}^{\tau}\right)$,

$$
X_{i}=\left(\mu_{i}-M^{\mu}, \sigma_{i}-M^{\sigma}, \tau_{i}-M^{\tau}\right) .
$$

We will use two common norm definitions for the vector defined in Equation (9) such that each student can be identified globally by a single scalar. This is a transformation of the data from the separate parameters to a scalar number which can capture maybe a more complex relationship between response time and cognitive disorders. The first norm is the Euclidean defined as,

$$
\left\|\mathrm{X}_{\mathrm{i}}\right\|_{2}=\left(\left(\mu_{\mathrm{i}}-\mathrm{M}^{\mu}\right)^{2}+\left(\sigma_{\mathrm{i}}-\mathrm{M}^{\sigma}\right)^{2}+\left(\tau_{\mathrm{i}}-\mathrm{M}^{\tau}\right)^{2}\right)^{1 / 2} .
$$


The second norm definition used here is the norm of the maximum,

$$
\left\|\mathbf{X}_{\mathbf{i}}\right\|_{\infty}=\max \left(\left|\mu_{\mathrm{i}}-\mathbf{M}^{\mu}\right|,\left|\sigma_{\mathrm{i}}-\mathrm{M}^{\sigma}\right|,\left|\tau_{\mathrm{i}}-\mathrm{M}^{\tau}\right|\right) \text {. }
$$

Figure 9 shows the curves for the norms defined above applied to the vector in Equation (8) as a function of the student label. The highest peaks in the plot represent the students whose ex-Gaussian parameters lie furthest from the respective modes. In this case, the students labeled as 5, 34, 41, 58, $80,110,131,137,142,169,185,186,189$ represent the 13 students ranking highest ( $7 \%$ of 190$)$ for both norms.
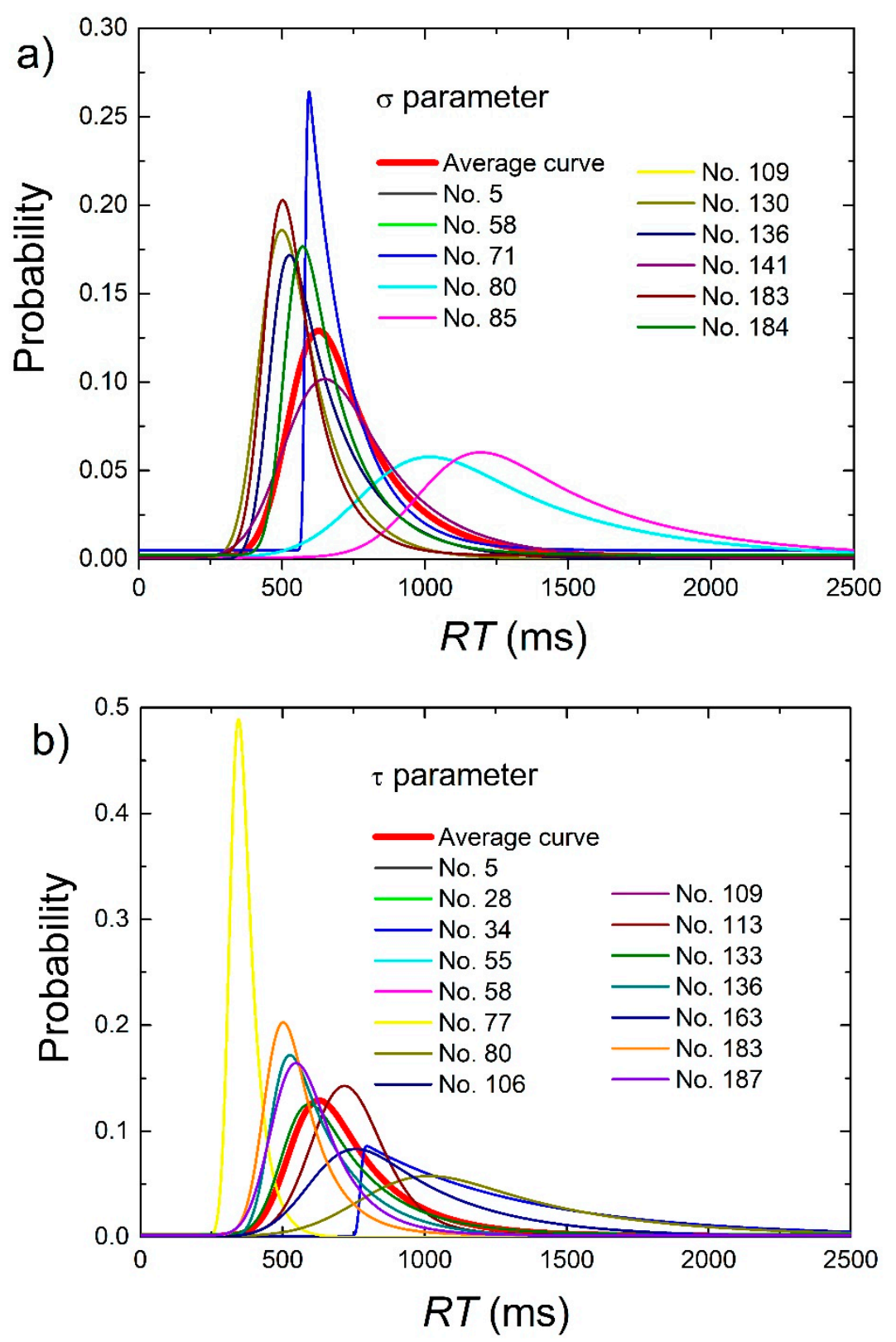

Figure 8. Probability distributions of the candidates resulting from the probability distribution of $\sigma$ (a) and $\tau(\mathbf{b})$ parameters of the ex-Gaussian probability density. The average curve has also been included. 

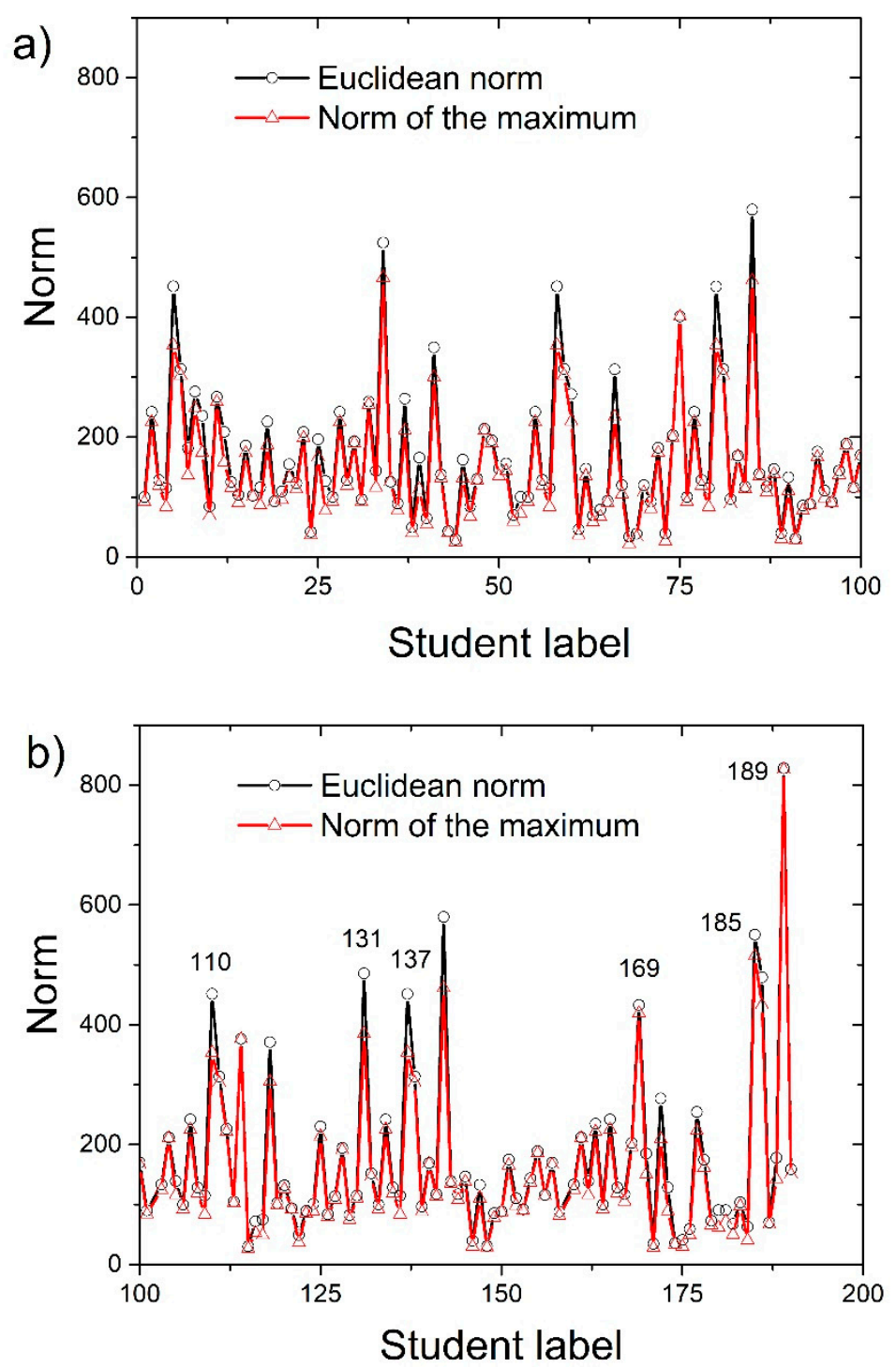

Figure 9. Euclidean norm and the norm of the maximum applied to the vector defined in Equation (8) as a function of the student label. In the upper panel, students from 1 to 100 are shown, and in the lower panel, students from 101 to 200. The students labeled as 110 (M), 131 (F), 137 (M), 169 (F), 185 (M), and 189 (F) appear in this classification only. The letter " $\mathrm{M}$ " between parentheses stands for male and the letter " $\mathrm{F}$ " for female.

\section{Conclusions}

A classification methodology based on response time data was proposed towards a quick pre-diagnosis of attention deficit or any another related cognitive disorder. The mode of the probability distributions of the RTs and the three parameters from an ex-Gaussian representation of the RT data were used to identify a number of children from the sample with non-normative behavior according to the world prevalence percentage of ADHD. Our methodology took into account the skewness of the probability distributions of the four parameters. The prevalence percentage was then split into the slow and fast RT regions proportionally to the percentage of counts at both sides of the mode of the probability distribution function. It should be pointed out that the candidates falling in the very fast region of the RT distribution may include skilled children who are able to respond fast and correctly. In general, a complementary criterion such as the number of mistakes made by the child can help select the candidates for ADHD among the fast-responding children. We provide a number of classification possibilities, all of them based on the prevalence percentage and the probability 
distributions of the mode and ex-Gaussian parameters. Among them, a classification based on the distance of the ex-Gaussian parameters to their respective mode which constitute the components of a vector whose norm serves as a unique, global scalar identifier of each child. We would like to point out that the validity of this work is not limited to ADHD pre-diagnosis but to identifying children with attention and cognitive disorders in general. Our methodology could also be adapted to cognitive disorders in elderly people, as they clearly correlate with slower response time as well. The development of objective instruments is highly desirable as methodologies available nowadays are not based on direct measurements but on interviewing people related to the child, and are known to lead to an over-diagnosis of ADHD. Although the ultimate diagnosis must be made by a psychologist, the selection provided by our methodology will allow them to focus on assessing a smaller number of children that would help save time and other resources. We aimed to develop a simple, fast automated methodology based on the response time as another step towards the diagnosis of cognitive disorders.

Author Contributions: E.N.-P. conceived and designed the experiments; M.H.-G. and E.N.-P. performed the experiments; all authors analyzed the data; J.C.C.-P., J.M.I. and P.F.-d.-C. contributed to the development of analysis tools; J.C.C.-P. and E.N.-P. wrote the paper. All authors read and approved the final manuscript.

Funding: This research was supported by grant no. RTI2018-102256-B-I00 (Spain).

Acknowledgments: The authors would like to thank everyone who made this research possible for the kind and generous collaboration, namely, the Conselleria d' Educació, Investigació, Cultura i Esport of the Generalitat Valenciana, La Patacona Primary School in Alboraya (Valencia, Spain), the children who participated in the experiments and their families, as well as the students from the Universitat de València who kindly volunteered during the realization of the experiments.

Conflicts of Interest: The authors declare no conflict of interest.

\section{References}

1. Sroubek, A.; Kelly, M.; Li, X. Inattentiveness in attention-deficit/hyperactivity disorder. Neurosci. Bull. 2013, 29, 103-110. [CrossRef] [PubMed]

2. Clauss-Ehlers, C.S. (Ed.) Encyclopedia of Cross-Cultural School Psychology; Springer Science \& Business Media LLC: Boston, MA, USA, 2010.

3. American Psychiatric Association. American Psychiatric Association Diagnostic and Statistical Manual of Mental Disorders, 5th ed.; APA: Washington, DC, USA, 2013.

4. Barkley, R.A. Attention Deficit Hyperactivity Disorder: A Handbook for Diagnosis and Treatment, 3rd ed.; Guilford: New York, NY, USA, 2006.

5. DuPaul, G.J.; Volpe, R.J.; Jitendra, A.K.; Lutz, J.G.; Lorah, K.S.; Gruber, R. Elementary school students with AD/HD: Predictors of academic achievement. J. Sch. Psychol. 2004, 42, 285-301. [CrossRef]

6. Sonuga-Barke, E.; Koerting, J.; Smith, E.; McCann, D.C.; Thompson, M. Early detection and intervention for attention-deficit/hyperactivity disorder. Expert Rev. Neurother. 2011, 11, 557-563. [CrossRef] [PubMed]

7. Lavigne Cerván, R.; Romero-Pérez, J.F. The Attention Deficit Hyperactivity Dissorder; Ediciones Pirámide: Madrid, Spain, 2010; (In Spanish, EL TDAH).

8. Pliszka, S. Practice parameter for the assessment and treatment of children and adolescents with attention-deficit/hyperactivity disorder. J. Am. Acad. Child Adolesc. Psychiatry 2007, 46, 894-921. [CrossRef]

9. Tarantino, S.C.; Mogentale, C.; Bisiacchi, P.S. Time-on-Task in Children with ADHD: An ex-Gaussian Analysis. Vincenza J. Int. Neuropsychol. Soc. 2013, 19, 820-828. [CrossRef]

10. Klein, C.; Wendling, K.; Huettner, P.; Ruder, H.; Peper, M. Intra-subject variability in attention-deficit hyperactivity disorder. Biol. Psychiatry 2006, 60, 1088-1097. [CrossRef] [PubMed]

11. Nigg,J.T.; Willcutt, E.G.; Doyle, A.E.; Sonuga-Barke, E.J. Causal heterogeneity in attention-deficit/hyperactivity disorder: Do we need neuropsychologically impaired subtypes? Biol. Psychiatry 2005, 57, 1224-1230. [CrossRef] [PubMed]

12. Willcutt, E.G.; Doyle, A.E.; Nigg, J.T.; Faraone, S.V.; Pennington, B.F. Validity of the executive function theory of attention-deficit/hyperactivity disorder: A meta-analytic review. Biol. Psychiatry 2005, 57, 1336-1346. [CrossRef] 
13. Castellanos, F.X.; Sonuga-Barke, E.J.; Scheres, A.; Di Martino, A.; Hyde, C.; Walters, J.R. Varieties of attention-deficit/hyperactivity disorder-related intra-individual variability. Biol. Psychiatry 2005, 57, 1416-1423. [CrossRef]

14. Luce, R.D. Response Times: Their Role in Inferring Elementary Mental Organization; Oxford University Press: New York, NY, USA, 1986.

15. Hockley, W.E.; Corballis, M.C. Test of serial scanning in item recognition. Can. J. Psychol. 1982, 36, $189-212$. [CrossRef]

16. Ratcliff, R.; Murdock, B.B. Retrieval processes in recognition memory. Psychol. Rev. 1976, 83, $190-214$. [CrossRef]

17. Gmehlin, D.; Fuermaier, A.B.M.; Walther, S.; Debelak, R.; Rentrop, M.; Westermann, C.; Sharma, A.; Tucha, L.; Koerts, J.; Tucha, O.; et al. Intraindividual Variability in Inhibitory Function in Adults with ADHD—An Ex-Gaussian Approach. PLoS ONE 2014, 9, e112298. [CrossRef]

18. Adamo, N.; Hodsoll, J.; Asherson, P.; Buitelaar, J.K.; Kuntsi, J. Ex-Gaussian, Frequency and Reward Analyses Reveal Specificity of Reaction Time Fluctuations to ADHD and Not Autism Traits. J. Abnorm. Child Psychol. 2019, 47, 557-567. [CrossRef]

19. Burbeck, S.L.; Luce, R.D. Evidence from auditory simple reaction times for both change and level detectors. Percept. Psychophys. 1982, 32, 117-133. [CrossRef]

20. Heathcote, A.; Popiel, S.J.; Mewhort, D.J.K. Analysis of response time distributions: An example using the Stroop task. Psychol. Bull. 1991, 109, 340-347. [CrossRef]

21. Matzke, D.; Wagenmakers, E.-J. Psychological interpretation of the ex-Gaussian and shifted Wald parameters: A diffusion model analysis. Psychon. Bull. Rev. 2009, 16, 798-817. [CrossRef]

22. Shahar, N.; Teodorescu, A.R.; Karmon-Presser, A.; Anholt, G.E.; Meiran, N. Memory for Action Rules and Reaction Time Variability in Attention-Deficit/Hyperactivity Disorder. Biol. Psychiatry Cogn. Neurosci. Neuroimaging 2016, 1, 132-140. [CrossRef]

23. Leth-Steensen, C.; King Elbaz, Z.; Douglas, V.I. Mean response times, variability, and skew in the responding of ADHD children: A response time distributional approach. Acta Psychol. 2000, 104, 167-190. [CrossRef]

24. Navarro-Pardo, E.; Navarro-Prados, A.B.; Gamermann, D. Moret-Tatay, C. Differences between younger and older university students on lexical decision task: Evidence through an ex-Gaussian approach. J. Gen. Psychol. 2013, 140, 251-268. [CrossRef]

25. Lemus-Zúñiga, L.G.; Navarro-Pardo, E.; Moret-Tatay, C.; Pocinho, R. Serious games for elderly continuous monitoring. In Data Mining in Clinical Medicine; Springer: New York, NY, USA, 2015; pp. 259-267. [CrossRef]

26. Moret-Tatay, C.; Moreno-Cid, A.; Argimon, I.I.D.L.; Quarti Irigaray, T.; Szczerbinski, M.; Murphy, M.; Vázquez-Martínez, A.; Vázquez-Molina, J.; Sáiz-Mauleon, B.; Navarro-Pardo, E.; et al. The effects of age and emotional valence on recognition memory: An ex-Gaussian components analysis. Scand. J. Psychol. 2014, 55, 420-426. [CrossRef] [PubMed]

27. Moret-Tatay, C.; Irigaray, T.Q.; Oliveira, C.; Argimon, I.I.D.L. Reaction Times as a dependent variable of memory: Future lines of research through an ex-Gaussian fit. Horiz. Neurosci. Res. 2015, 17, 60-71.

28. Hohle, R.H. Inferred components of reaction times as functions of foreperiod duration. J. Exp. Psychol. 1965, 69, 382-386. [CrossRef]

29. Borella, E.; de Ribaupierre, A.; Cornoldi, C.; Chicherio, C. Beyond interference control impairment in ADHD: Evidence from increased intraindividual variability in the color-Stroop test. Child Neuropsychol. 2012, 19, 495-515. [CrossRef] [PubMed]

30. World Medical Association. Declaration of Helsinki: Ethical Principles for Medical Research Involving Human Subjects. J. Am. Med. Assoc. 2013, 310, 2191-2194. [CrossRef]

31. Forster, K.I.; Forster, J.C. DMDX: A windows display program with millisecond accuracy. Behav. Res. Methods Instrum. Comput. 2003, 35, 116-124. [CrossRef]

32. Fan, J.; McCandliss, B.D.; Sommer, T.; Raz, A.; Posner, M.I. Testing the efficiency and independence of attentional networks. J. Cogn. Neurosci. 2002, 14, 340-347. [CrossRef]

33. Posner, M.I.; Dehaene, S. Attentional networks. Trends Neurosci. 1994, 17, 75-79. [CrossRef]

34. Posner, M.I.; Raichle, M.E. Images of Mind; Scientific American Library: New York, NY, USA, 1994.

35. Lacouture, Y.; Cousineau, D. How to use MATLAB to fit the ex-Gaussian and other probability functions to a distribution of response times. Tutor. Quant. Methods Psychol. 2008, 4, 35-45. [CrossRef] 
36. Ratcliff, R.; McKoon, G. The diffusion decision model: Theory and data for two-choice decision tasks. Neural Comput. 2008, 20, 873-922. [CrossRef] [PubMed]

37. Ratcliff, R. Group reaction time distributions and an analysis of distribution statistics. Psychol. Bull. 1979, 86, 446-461. [CrossRef] [PubMed]

38. Moret-Tatay, C.; Gamermann, D.; Navarro-Pardo, E.; Fernández-de-Córdoba-Castellá, P. ExGUtils: A python package for statistical analysis with the ex-Gaussian probability density. Front. Psychol. 2018, 9, 1-11. [CrossRef]

39. Levenberg, K. A method for the solution of certain non-linear problems in least squares. Q. Appl. Math. 1944, 2, 164-168. [CrossRef]

40. Marquardt, D. An algorithm for least-squares estimation of nonlinear parameters. J. Soc. Ind. Appl. Math. 1963, 11, 431-441. [CrossRef]

41. Castellanos, F.X.; Sonuga-Barke, E.J.; Milham, M.P.; Tannock, R. Characterizing cognition in ADHD: Beyond executive dysfunction. Trends Cogn. Sci. 2006, 10, 117-123. [CrossRef]

42. Emond, V.; Joyal, C.; Poissant, H. Neuroanatomie structurelle et fonctionnelle du trouble déficitaire d'attention avec ou sans hyperactivité (TDAH) [Structural and functional neuroanatomy of attention-deficit hyperactivity disorder (ADHD)]. Encephale 2009, 35, 107-114. (In French) [CrossRef] [PubMed]

43. Reinhardt, M.C.; Reinhardt, C.A. Attention deficit-hyperactivity disorder, comorbidities, and risk situations. J. Pediatr. (Rio. J.) 2013, 89, 124-130. [CrossRef] [PubMed]

44. Hwang-Gu, S.L.; Chen, Y.C.; Liang, S.H.; Ni, H.C.; Lin, H.Y.; Lin, C.F.; Gau, S.S. Exploring the Variability in Reaction Times of Preschoolers at Risk of Attention-Deficit/Hyperactivity Disorder: An ex-Gaussian Analysis. J. Abnorm. Child Psychol. 2019. [CrossRef] [PubMed]

(C) 2019 by the authors. Licensee MDPI, Basel, Switzerland. This article is an open access article distributed under the terms and conditions of the Creative Commons Attribution (CC BY) license (http://creativecommons.org/licenses/by/4.0/). 